\title{
Severe gestational gigantomastia: management challenges
}

\author{
A Rooi, ${ }^{1,2}$ (i) A Botha, ${ }^{1,3}$ (iD) E Ndobe, ${ }^{1,3}$ (iD) M Nel ${ }^{(1 D}$ \\ ${ }^{1}$ Department of Surgery, Division of Plastic and Reconstruction Surgery, University of the Witwatersrand, South Africa \\ ${ }^{2}$ Department of Surgery, Helen Joseph Hospital, South Africa \\ ${ }^{3}$ Department of Surgery, Chris Hani Baragwanath Academic Hospital, South Africa
}

Corresponding author, email: adelaiderooi@yahoo.com

\begin{abstract}
Summary
Gestational gigantomastia is rare and characterised by rapid and disproportionate enlargement of the breast during pregnancy. It often requires surgical removal of more than $1500 \mathrm{~g}$ of breast tissue. Of the 50 case reports published worldwide, not one was in South African literature. This unusual case report is of a female presenting with gigantomastia at five weeks gestational age. The patient was multiparous and decided to terminate the pregnancy due to the physical and emotional effects of the large, pendulous breasts. Management included breast reduction and free nipple grafting in a staged approach. The complications are briefly outlined. Despite rare presentation, patient satisfaction was achieved.

Keywords: severe gestational gigantomastia, disproportionate enlargement, breast, pregnancy, mastectomy
\end{abstract}

\section{Case report}

The patient was a 35 -year-old female, five weeks pregnant (gravida 4 para 3 ) at the time, who presented to our outpatient department in severe emotional distress due to rapidly and continuously enlarging breasts, noticed since the third week of her gestation. Her other complaints were physical impairment in the form of mastalgia, back, shoulder and neck pain, dyspnoea, difficulty mobilising and performing activities of daily living. The patient denied any of these symptoms pre-existing prior to her pregnancy. Her pre-partum brassiere size was 36 C. On presentation, no commercially available brassiere could fit her. She had previous uncomplicated term pregnancies and has three healthy children. During her previous pregnancies, she had physiological pregnancy-induced breast hypertrophy with return to her usual partum brassiere size (36 C) after partition and cessation of lactation. No other comorbidities were reported, and her HIV status was non-reactive. Except for being obese, she was an otherwise healthy female with no family history of note and no medication use or previous operations.

The patient was offered an operation postpartum. She elected to terminate the pregnancy even after extensive counselling with a psychologist. No desire for future pregnancies was reported as she was multiparous and subsequently had a bilateral tubal ligation.

On examination, the patient was systemically well, with a body mass index (BMI) of $39 \mathrm{~kg} / \mathrm{m}^{2}$ (weight $=105 \mathrm{~kg}$, height $=1.63 \mathrm{~m}$ ). Her breast examination showed bilateral grade III ptosis with peau d'orange, hyperpigmented skin and striae. On palpation, no lumps or axillary lymphadenopathy were detected. The sternal notch to nipple measurements were
$47 \mathrm{~cm}$ on the right and $44 \mathrm{~cm}$ on the left. The nipple to infra mammary fold (IMF) measured $34 \mathrm{~cm}$ on the right and 33 $\mathrm{cm}$ on the left. Breast circumferences were $44 \mathrm{~cm}$ right and $40 \mathrm{~cm}$ left. Blood counts and kidney function were within normal limits with haemoglobin: $11.1 \mathrm{~g} / \mathrm{dl}$, thyroid function test was within normal limits, no other hormonal tests were performed. In consultation with the radiologist, no breast imaging was performed in view of her extreme mastalgia and low likelihood of adequate imaging obtainable due the excessive breast hypertrophy and oedema.

Six weeks post termination of pregnancy, a right breast reduction with preservation of a superior breast mound and free nipple graft was performed under general anaesthesia. The weight of the inferiorly excised breast tissue was $7815 \mathrm{~g}$. Due to excessive bleeding from massive feeder breast vessels her intraoperative haemoglobin dropped to $6.3 \mathrm{~g} / \mathrm{dl}$. The patient required a massive transfusion protocol of four units of packed red blood cells, four units of fresh frozen plasma and one unit of platelets. The procedure was terminated after skin closure and postponed to a few days later. Post transfusion, the haemoglobin increased to $10.4 \mathrm{~g} / \mathrm{dl}$ and it was elected to transfuse an additional unit of packed red blood cells preoperatively. Three days later, the left breast reduction and free nipple graft were done. The weight of the excised left breast tissue was $5175 \mathrm{~g}$, which brought the total excised weight to $12990 \mathrm{~g}$. The patient required an additional transfusion of two units of packed red blood cells intraoperatively, while the rest of the surgery was uneventful. She was discharged 48 hours postoperatively without any complications.

On the outpatient follow-up one week postoperatively, there was a $70 \%$ loss of the left free nipple graft and angle of sorrow dehiscence. She was subsequently re-admitted 


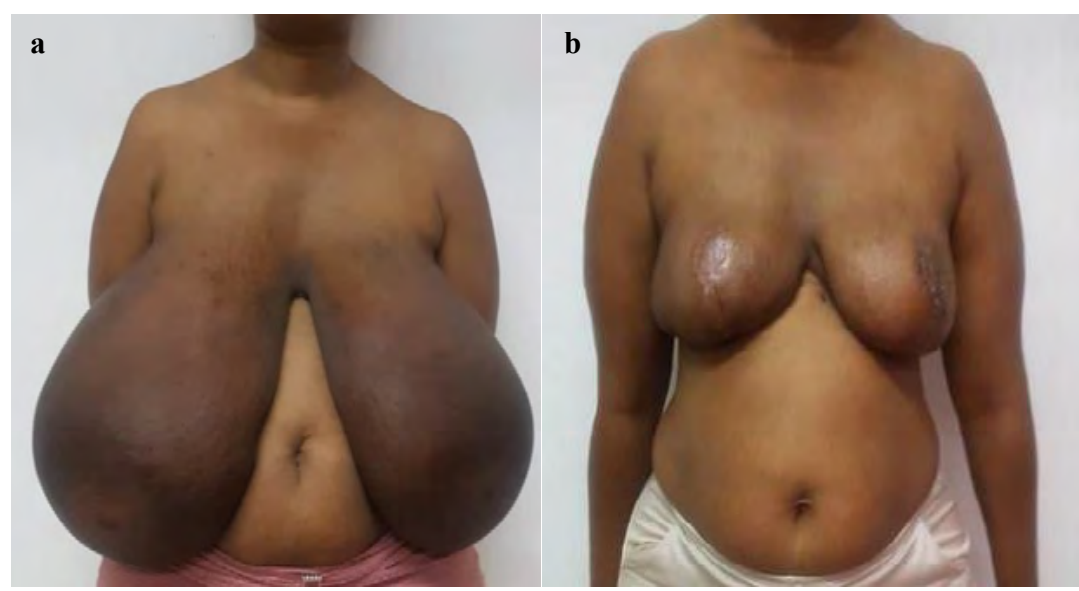

Figure 1: Frontal views

a) Preoperatively

b) One month postoperatively

for debridement (failed conservative management) and fullthickness skin graft of the nipple-areola complex. Twentyeight days postoperatively the patient had good healing and $100 \%$ graft take. Histological evaluation of the excised breast tissue showed no malignancy. Figure 1 shows preoperative and postoperative results.

\section{Discussion}

Gestational gigantomastia is defined as rapid and disproportionate growth of breast during pregnancy. ${ }^{1}$ Another definition is breast enlargement requiring more than $1500 \mathrm{~g}$ of breast tissue removal. ${ }^{2}$ Gigantomastia can be divided into four major types based on aetiology, namely idiopathic, juvenile (puberty associated), gestational and drug induced. ${ }^{3}$ Because gestational gigantomastia is rare, ( 1 in 100000 pregnancies $),{ }^{2}$ the aetiology is not well understood. It is thought to be triggered by placental hormones, in view of excessive increase in breast size seen most frequently during the first trimester or early second trimester when gonadotropin is at its highest level. ${ }^{4}$ Gestational gigantomastia can lead to skin ulceration, infection, tissue necrosis, and septicemia. ${ }^{5}$ Hedberg et al. found that conservative treatment with bromocriptine halts breast growth but does not reduce breast size, and therefore, surgical treatment remains the mainstay of therapy. ${ }^{6}$

The main surgical approaches are reduction mammoplasty and mastectomy. ${ }^{7}$ Mastectomy is the gold standard of treatment because breast-conserving surgery has a very high recurrence rate in subsequent pregnancies as proven by Swelstad and other authors. ${ }^{8,9}$ Excised breast tissue in different studies varied between $3750 \mathrm{~g} / 3700 \mathrm{~g},{ }^{3} 8000 \mathrm{~g} / 7155 \mathrm{~g},{ }^{10} 10000 \mathrm{~g}$ per breast, ${ }^{11}$ and $8000 \mathrm{~g}$ bilaterally. ${ }^{1}$ Complications following mastectomy and breast reduction included intraoperative haemorrhage, haemodynamic instability, anaemia and areola necrosis. ${ }^{3}$

Although mastectomy is the mainstay of treatment for gestational gigantomastia, breast reduction was performed on this patient, because her family was complete and therefore, she would not have a recurrence of gestational gigantomastia. An advantage to breast conservation is that the patient will not require delayed breast reconstruction.

However, wound healing complications and skin graft loss should be anticipated, especially in obese patients. In our experience, a one-stage approach with two teams (a team on each breast) or a staged, two team approach and availability of intraoperative blood and blood products may aid in reducing complications.

\section{Conflict of interest}

The authors declare no conflict of interest.

\section{Funding source}

None.

\section{Ethical approval}

Ethical approval was obtained through the University of the Witwatersrand Medical School Human Research Ethics Committee (HREC) (medical) with certificate number: M2010114. The patient gave consent as per hospital protocol before surgery.

\section{Consent for publication}

The patient gave written consent to her case being anonymously published in a suitable medical journal.

\section{ORCID}

A Rooi (iD https://orcid.org/0000-0003-2647-491X

A Botha (iD https://orcid.org/0000-0003-0162-5582

E Ndobe (iD https://orcid.org/0000-0002-3930-4066

$\mathrm{M} \mathrm{Nel}$ (iD https://orcid.org/0000-0002-8206-3392

\section{REFERENCES}

1. Lapid O. Breast reconstruction after mastectomy for gestational gigantomastia. Aesthetic Plast Surg. 2013;37(2):38891. https://doi.org/10.1007/s00266-012-0054-4.

2. Dancey A, Khan M, Dawson J, Peart F. Gigantomastia - a classification and review of the literature. J Plast Reconstr Aesthet Surg. 2008;61:493-502. https://doi.org/10.1016/j. bjps.2007.10.041

3. Türkan H, Gökgöz MS, Tasdelen I, HZ Dündar. Gestational gigantomastia. J Breast Health. 2016;12(2):86-7. https://doi. org/10.5152/tjbh.2016.2852.

4. Zargar AH, Laway BA, Masoodi SR, et al. Gestational macromastia not responding to termination of pregnancy. Postgrad Med J. 1995;71(832):124-5. https://doi.org/10.1136/ pgmj.71.832.124-b.

5. Shoma A, Elbassiony L, Amin M, et al. Gestational gigantomastia - a review article and case presentation of a new surgical management option. Surg Innov. 2011;18(1):94101. https://doi.org/10.1177/1553350610391106.

6. Hedberg K, Karlson K, Lindstedt G. Gigantomastia during pregnancy - effect of dopamine agonist. Am J Obstet Gynecol. 1979;133(8):928-31. https://doi.org/10.1016/00029378(79)90316-8.

7. Mangla M, Singla D. Gestational gigantomastia - a systemic review of case reports. J Mid Life Health. 2017;8:40-4. https:// doi.org/10.4103/jmh.JMH_92_16.

8. Swelstad MR, Swelstad BB, Rao VK, Gutowski KA. Management of gestational gigantomastia. Plast Reconstr Surg. 2006;118(4):840-8. https://doi.org/10.1097/01.prs.0000 232364.40958.47.

9. Moazzami B, Chaichian S, Farahvash M, et al. A rare case of gestational gigantomastia with hypercalcemia - the challenges of management and follow up. J Reprod Infertil. 2016;17(4):243-6. 
10. Boghdadly SEI, Pitkanen J, Hassonah M, Al Saghier M. Emergency mastectomy in gigantomastia of pregnancy - a case report and literature review. Ann of Saudi Med. 1997;17(2):220-2. https://doi.org/10.5144/0256-4947.1197.2 20.
11. Antevski B, Jovkovski O, Filipovski V, Banev S. Extreme gigantomastia in pregnancy: case report - my experience with two cases in last 5 years. Arch Gynecol Obstet. 2011;284(3):575-8. http://doi.org/10.1007/s00404-010-17148. 